\title{
Cloudy sounding and cloud-top height retrieval from AIRS alone single field-of-view radiance measurements
}

(a) Cooperative Institute for Meteorological Satellite Studies

University of Wisconsin-Madison

Madison, Wisconsin, U.S.A.

\# Chemistry \& Dynamics Branch, Science Directorate

NASA Langley Research Center

Hampton, VA 23681, U.S.A.

\& Satellite Meteorology and Climatology Division

NOAA/NESDIS/Office of Research and Applications

5200 Auth Road

Camp Springs, Maryland, U.S.A.

+ Department of Atmospheric Sciences

Texas A\&M University

College Station, Texas, U.S.A.

26 High-spectral resolution measurements from the Atmospheric Infrared Sounder (AIRS)

27 onboard the EOS (Earth Observing System) Aqua satellite provide unique information

28 about atmospheric state, surface and cloud properties. This paper presents an AIRS alone

29 single field-of-view (SFOV) retrieval algorithm to simultaneously retrieve temperature,

30 humidity and ozone profiles under all weather conditions, as well as cloud top pressure

31 (CTP) and cloud optical thickness (COT) under cloudy skies. For optically thick cloud

32 conditions the above-cloud soundings are derived, whereas for clear skies and optically

33 thin cloud conditions the profiles are retrieved from $0.005 \mathrm{hPa}$ down to the earth's

34 surface. Initial validation has been conducted by using the operational MODIS (Moderate 
35 Resolution Imaging Spectroradiometer) product, ECMWF (European Center of Medium-

36 range Weather Forecasts) analysis fields and radiosonde observations (RAOBs). These

37 inter-comparisons clearly demonstrate the potential of this algorithm to process data from

38 high-spectral infrared (IR) sounder instruments.

39

40

41

42

43

44

45

46

47

48

49

50

51

52

53

54

55

56

57 
59 The AIRS instrument measures radiances in 2378 spectral channels within the spectral 60 range from $650 \mathrm{~cm}^{-1}$ to $2675 \mathrm{~cm}^{-1}$ (corresponding to $3.74 \mu \mathrm{m}$ to $15.4 \mu \mathrm{m}$ ). The spectral 61 coverage includes strong $\mathrm{CO}_{2}$ absorption necessary for temperature profile retrievals,

62 window regions that are used for retrieving the surface and cloud properties, and a strong 63 water vapor absorption band for humidity soundings. The maximum scanning angle of 64 AIRS is 49.5 degrees, the swath width is $1650 \mathrm{~km}$, and the footprint size is $13.5 \mathrm{~km}$ at 65 nadir. More specifications about the AIRS instrument can be found elsewhere [e.g., 66 Aumann et al., 2003; Chahine et al., 2006]. Since one footprint (due to its size) contains 67 clear and/or cloudy scenes with varying properties (e.g., fraction, height, phase), 68 sounding retrievals using AIRS-only measurements under all sky conditions are quite 69 challenging. According to Smith et al. [2005] there are essentially three ways to deal with 70 cloudy radiances: (1) assuming opaque cloud conditions, (2) cloud clearing, and (3) 71 making use of a physically based radiative transfer model. In approach (1) the sounding 72 retrievals can be derived down to the cloud top level. Cloud clearing combines the cloudy 73 radiances with clear measurements from another instrument; for example, AMSU

74 (Advanced Microwave Sounding Unit) radiances are used in the AIRS operational 75 retrieval system [Susskind et al., 2003], and MODIS measurements are used for AIRS 76 single FOV cloud clearing [Smith et al., 2004, Li et al., 2005b]. Approach (3) was first

77 applied on AIRS measurements in Smith et al. [2005]. Using measurements from the

78 aircraft sounder NPOESS (National Polar-orbiting Operational Environmental Satellite

79 System) Airborne Sounder Testbed - Interferometer (NAST-I) with high spatial 80 resolution (2 $\mathrm{km}$ at nadir) offers the advantage of cloudy FOVs with less varying cloud 
81 height and optical properties. Statistical and physical inversion methods using a cloudy

82 radiative transfer model have been developed to process NAST-I radiances for accurate

83 retrieval of temperature and moisture profiles below optically thin clouds [Smith et al.,

84 2005a; Zhou at al., 2005; 2007a; 2007b]. The algorithm for NAST-I cloudy sounding has

85 been adjusted to be suitable for AIRS footprint in this paper. The main differences

86 between the NAST-I method and AIRS cloudy sounding algorithm, as presented in this

87 paper, are that (1) the latter uses a different training set (global instead of regional and

88 seasonal), (2) assigns ice cloud-top and/or water cloud-top to each profile, the cloud-top

89 assignment is a little different from that in NASTI algorithm which assumes two cloud

90 levels and alters the profile to be isothermal blow the lower cloud level, (3) performs

91 different classification procedures in retrieval, (4) uses an IR technique to obtain the

92 cloud phase in the retrieval step, and (5) uses MODIS product for independent

93 comparisons. Initial results of inter-comparisons with the operational MODIS cloud-top

94 pressure (CTP) product, ECMWF analysis and radiosonde observations are promising for

95 the processing of data from future advanced IR sounder instruments like IASI (Infrared

96 Atmospheric Sounding Interferometer) and CrIS (Cross-track Infrared Sounder). 


\section{Methodology used for AIRS alone SFOV cloudy sounding}

109 The IMAPP AIRS retrieval software (latest version v1.3 was released in November

110 2006), which delivers atmospheric and surface parameters with a validity restricted to

111 clear skies, was used as the starting point for the cloudy retrieval methodology. The clear

112 sky algorithm is based on eigenvector regression. The regression training set [Borbas et

113 al., 2005] consists of approximately 15000 globally distributed profiles (including surface

114 parameters) and their associated computed radiances, which were generated by the Stand-

115 alone Radiative Transfer Algorithm (SARTA v106, Strow et al., 2003). The training set

116 is classified based on the brightness temperature (BT) in the longwave window region

117 and the AIRS viewing angles. In addition to the simulated IR radiances, the surface

118 pressure (extracted from analysis data provided by the National Centers of Environmental

119 Prediction, NCEP) and solar zenith angle are also used as predictors. The sounding

120 retrieval product, obtained at AIRS single FOV resolution, includes temperature,

121 humidity and ozone profiles, as well as surface skin temperature and surface emissivities.

122 The surface IR emissivities are retrieved at 10 IR wavenumber points. Detailed

123 information about the IMAPP AIRS retrieval algorithm under clear skies can be found in

124 Weisz et al. [2003; 2006].

125 From the regression training set $\sim 6200$ profiles can be assigned with a CTP between 126900 and $200 \mathrm{hPa}$ according to their relative humidity (RH). Out of these $\sim 2160$ profiles 
127 are assumed to be ice clouds (those with CTP $<450 \mathrm{hPa}$ ) whereas $\sim 4010$ profiles are 128 assumed to be water clouds (CTP $>400 \mathrm{hPa})$. Figure 1 displays the locations of the clear 129 profiles, as well as profiles with water clouds and ice clouds.

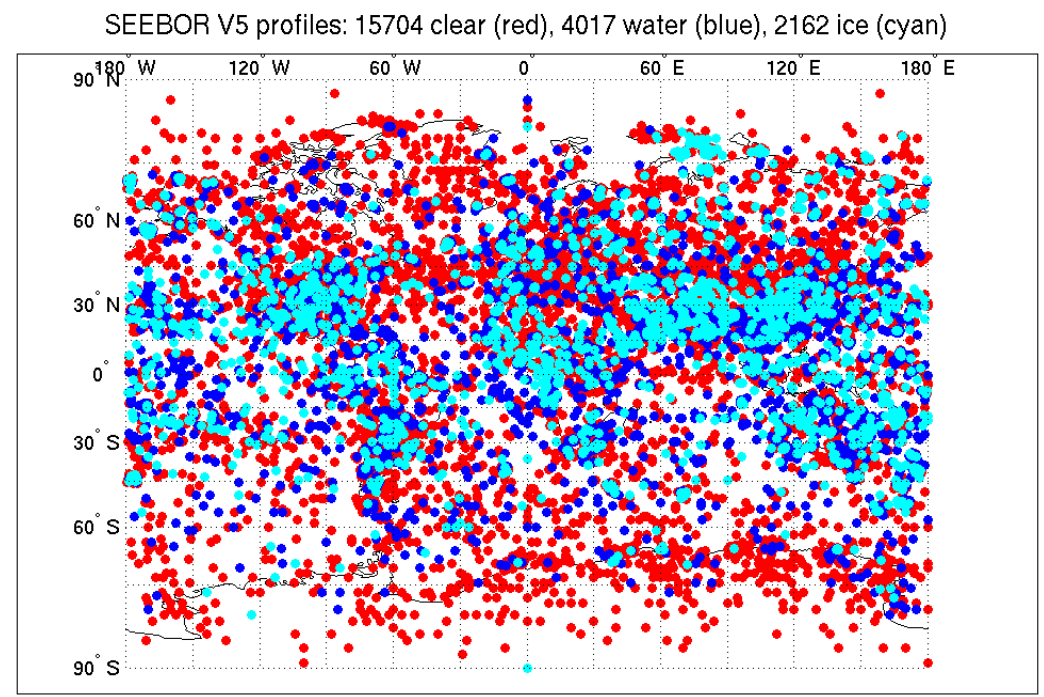

130

131 Figure 1. Global distribution of training set profiles. Clear sky pixels, water cloud and ice

132 cloud pixels are indicated as red, blue and cyan dots, respectively.

133 Cloud optical thickness (COT) values between 0.001 and 2 were assigned randomly

134 to each profile in both classes (water and ice). For ice clouds the effective particle radius

$135\left(\mathrm{R}_{\mathrm{e}}\right)$ was computed inserting COT into an equation that is given in Heymsfield et al.

136 [2003]. With a random error of $10 \%$ added to $\mathrm{R}_{\mathrm{e}}$, a range between 10 and $30 \mu \mathrm{m}$ was

137 obtained. For water clouds an effective particle radius distributed between 5 to $25 \mu \mathrm{m}$

138 was randomly assigned to the profiles. The assignment of COT and $\mathrm{R}_{\mathrm{e}}$ to the a profile is

139 similar to Zhou et al. [2005], although the CTP assignment is different.

140 Through joint efforts of the University of Wisconsin-Madison and Texas A\&M 141 University, a fast radiative transfer cloud model for hyperspectral IR sounder 142 measurements has been developed [Wei et al., 2004]. For ice clouds, the bulk single- 
143 scattering properties of ice crystals are derived by assuming aggregates for large particles

$144(>300 \mu \mathrm{m})$, hexagonal geometries for moderate particles $(50-300 \mu \mathrm{m})$ and droxtals for

145 small particles $(0-50 \mu \mathrm{m})$. For water clouds, spherical water droplets are assumed, and

146 the classical Lorenz-Mie theory is used to compute their single-scattering properties. In

147 the model input, the cloud optical thickness is specified in terms of its visible optical

148 thickness at $0.55 \mu \mathrm{m}$. The IR COT for each AIRS channel can be derived from the

149 visible COT. The cloudy radiance for a given AIRS channel can be computed by

150 coupling the clear sky optical thickness and the cloud optical effects. The clear sky

151 optical thickness is derived from the fast radiative transfer model SARTA. Once the

152 cloudy radiances have been calculated, a regression is performed to output two sets of

153 regression coefficients (water and ice). In addition to this classification based on the

154 cloud phase, the viewing angle classification is also applied in the cloudy retrieval 155 process.

156 A cloud phase detection method based on an IR technique [Strabala et al., 1994] is 157 applied to the AIRS BT spectrum for identifying clear, ice clouds, water clouds and 158 mixed phase clouds for a given AIRS footprint. If the pixel is clear, then the clear 159 regression coefficients are applied to the AIRS BT spectrum, and the retrieval is 160 performed as in version 1.3 of the IMAPP AIRS retrieval algorithm. One improvement to 161 the clear sky algorithm involves using emissivity eigenvectors in the regression [Zhou et 162 al., 2001; Smith et al., 2005b], and a hyperspectral emissivity spectrum is simultaneously 163 obtained along with the sounding products; a manuscript on handling hyperspectral 164 emissivities in sounding retrieval is under preparation. 
165 If the pixel is cloudy, then the appropriate set of coefficients is used depending on 166 the cloud phase. If the cloud phase is mixed, then the clouds are treated as ice clouds. If 167 the retrieved cloud optical thickness is less than 1.5 (i.e., optically thin clouds), the 168 sounding parameters are output from the top of the atmosphere down to the surface. In all 169 other cloud cases (i.e., optically thick clouds), the sounding parameters are retrieved 170 down to the cloud top pressure (CTP) level. In addition to temperature, humidity and 171 ozone, COT and CTP are retrieved for every cloudy pixel in a granule. 


\section{Results and preliminary validation}

193 Nighttime granule 11 on 08 September 2004 was chosen to illustrate the retrieval results.

194 Figure 2 shows the AIRS BT at wavenumber $911 \mathrm{~cm}^{-1}$ (top left) and the retrieved cloud

195 phase (top right) for this granule.
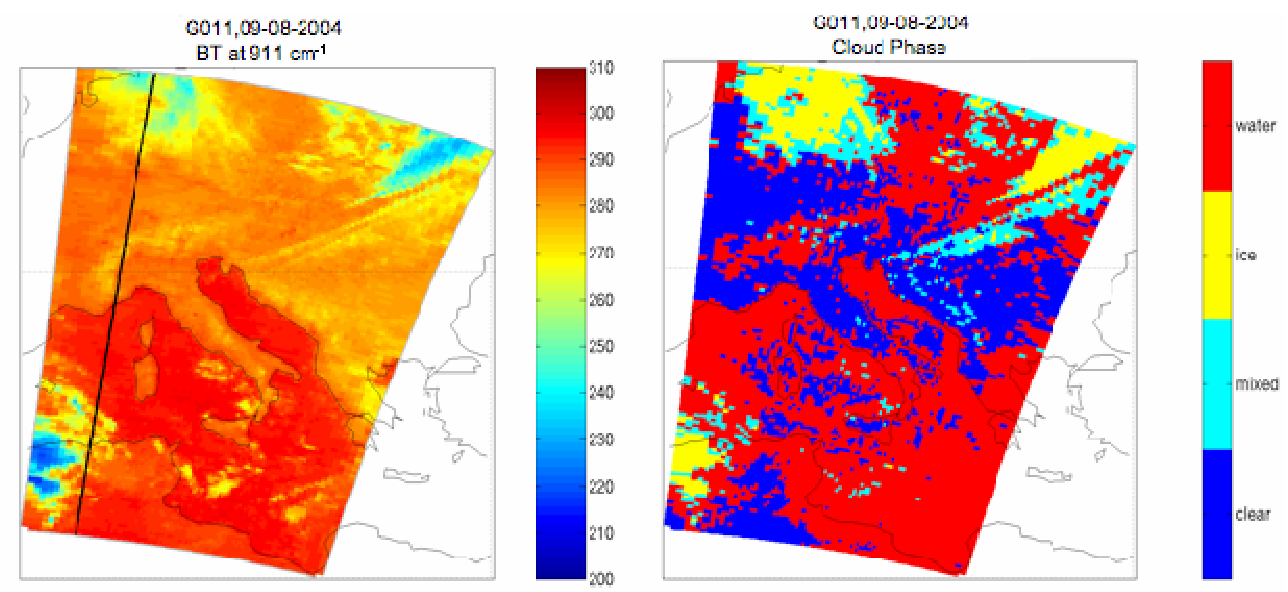

IMAFP AIRS Rettieval: G011,09-08-2004 Cloud Top Pressure [mbar]
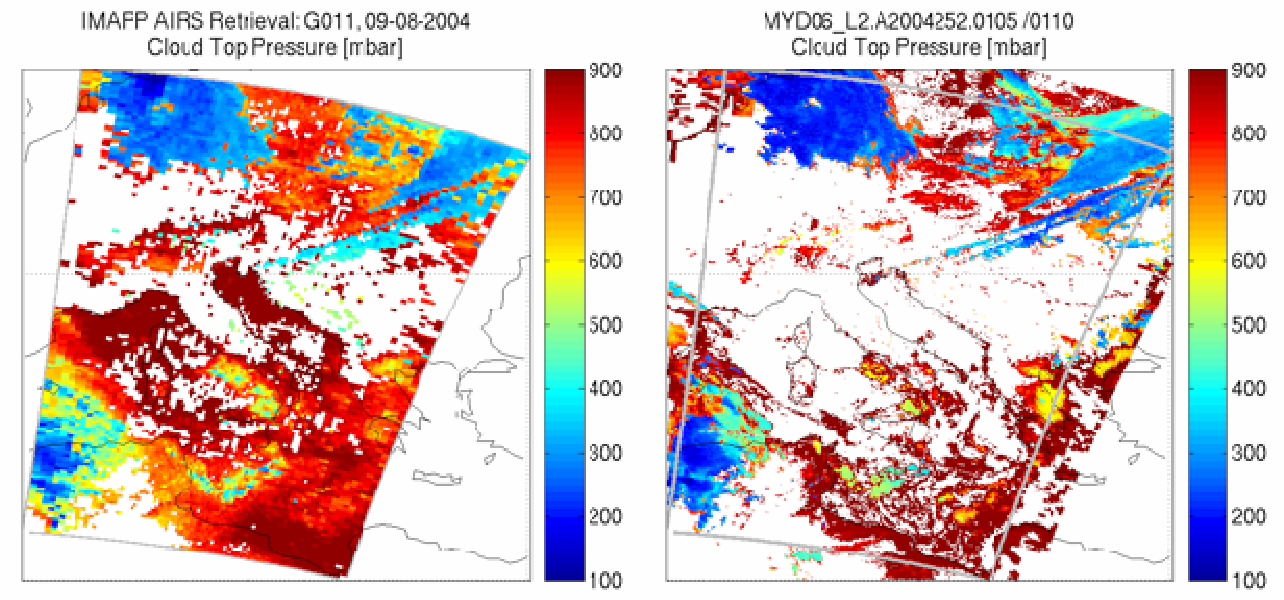
197 Figure 2. AIRS BT at wavenumber $911 \mathrm{~cm}^{-1}$ (top left), retrieved cloud phase (top right),

198 AIRS retrieved CTP (bottom left) and operational MODIS CTP (MYD06) product

199 (bottom right) for granule 11 on 08 September 2004.

200 The bottom panels of Figure 2 display the CTP retrieved by AIRS (left) and by

201 MODIS (right). It should be mentioned that the operational MODIS (MYD06) CTP

202 product uses sounding profiles from global forecasts, whereas the CTP from AIRS is

203 simultaneously retrieved with the sounding (temperature, moisture and ozone) profiles.

204 The CTP retrievals from AIRS agree very well with the operational MODIS CTP

205 product. Specifically, over the ocean (Mediterranean Sea) the AIRS single FOV

206 algorithm is capable of retrieving very reasonable values for lower clouds, whereas

207 MODIS provides no retrievals due to limited spectral information. The circular feature of

208 the thick cloud in the upper left corner of the granule depicts different cloud heights of

209 mixed and ice clouds as seen in the cloud phase panel of Figure 2.

210 To assess performance of the sounding retrieval algorithm under cloudy conditions a

211 cross section from north to south (as indicated in the BT panel of Figure 2 as a solid black

212 line) is examined and evaluated by comparing with the ECMWF model analysis (see

213 Figure 3). The ECMWF analysis data has been interpolated horizontally to the AIRS

214 pixels and vertically to 101 pressure levels that are used in the AIRS radiative transfer

215 calculation. The difference in time between the ECMWF analysis and the AIRS

216 measurements is about 70 minutes. The spatial resolution of the ECMWF analysis is 0.5

217 degrees. As mentioned above, the parameters are only retrieved to the CTP level when

218 optically thick clouds are present. For temperature (top panels of Figure 3) some minor

219 differences can be seen; for example, ECMWF analysis finds colder temperatures 
220 between $\sim 170$ and $200 \mathrm{hPa}$ for scanline 1 to 45 . Nevertheless, the general pattern of the

221 AIRS retrieved temperature field compares favorably with the ECMWF model.

222 Furthermore, relatively accurate temperature soundings are obtained under thin clouds as

223 can be seen in the area beyond scanline 105.
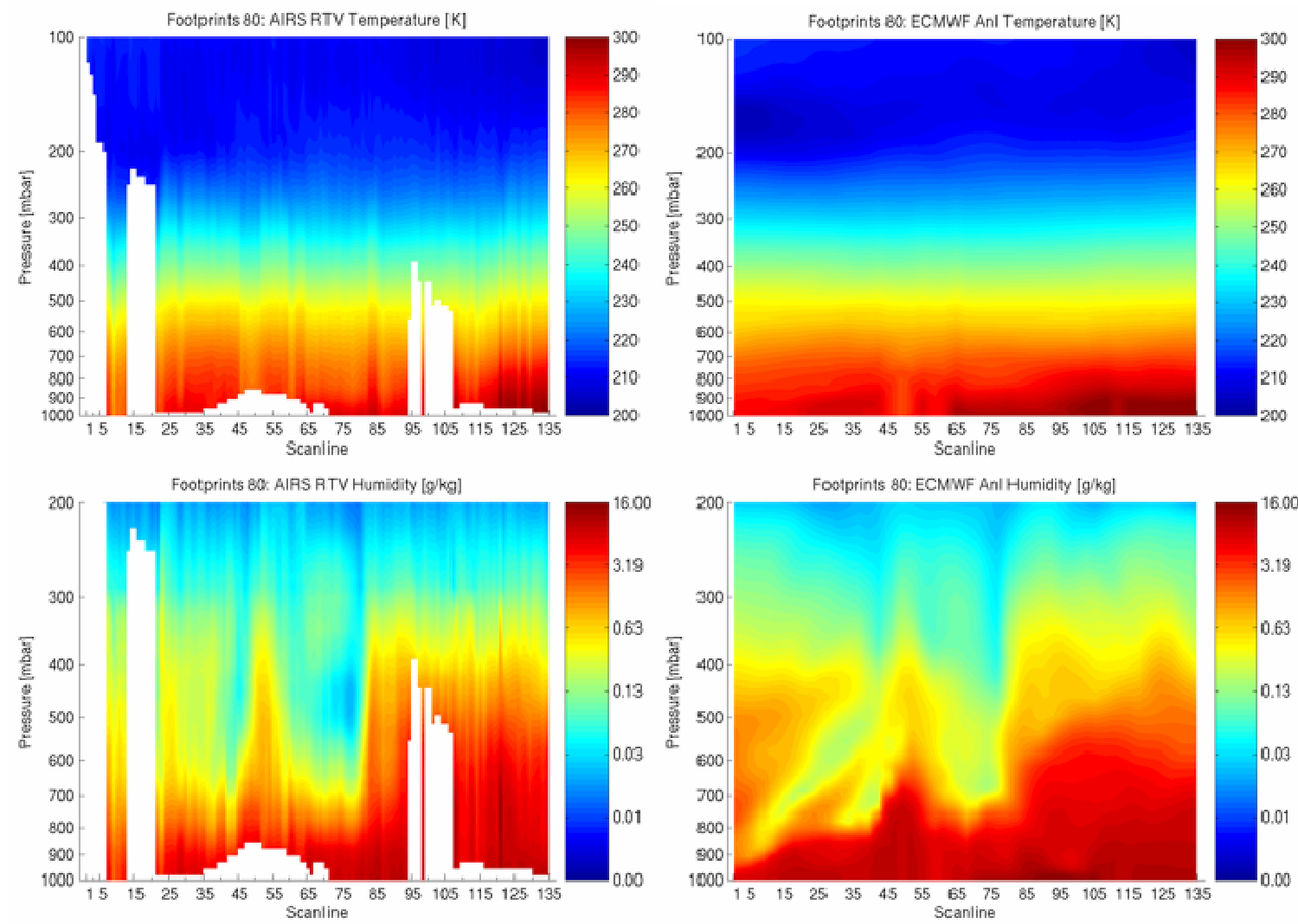

225 Figure 3. Temperature (top) and humidity (bottom) from the AIRS cloudy sounding

226 retrieval (left) and the ECMWF model analysis (right) for granule 11 on 08 September 2272004.

228 The same inter-comparison between AIRS and ECMWF was conducted for humidity

229 (bottom panels of Figure 3). The AIRS sounding retrieval successfully reproduces the

230 humidity variation shown in the ECMWF model analysis. Again in areas of thin or

231 broken clouds (e.g., between scanlines 7 and 13, and between 105 and 125) the cloudy 
232 retrieval achieves very reasonable values, which a clear sky sounding retrieval algorithm

233 would not be able to accomplish.

234 Root-mean-square errors of the retrieval deviations from the ECMWF fields (not

235 shown) offer further reassurance that the cloudy sounding algorithm is reasonably

236 accurate beneath broken and optically thin clouds. Differences between ECWMF and

237 AIRS are partly caused by the different spatial (horizontally and vertically) resolution and

238 by the difference in time.

239 It is also worth noting that atmospheric profile retrievals (including ozone) of the

240 layers above the cloud are not affected by the clouds below. That is particularly evident

241 for ozone profiles (not shown), where a clear sky only method yields unrealistic

242 stratospheric ozone values caused by clouds from lower levels. These disturbances are

243 not seen when using the cloudy sounding algorithm.

244 To further investigate the performance of the sounding retrieval, a co-located

245 radiosonde measurement within granule 11 (southern Italy) was used. The retrieved CTP

246 is $849.8 \mathrm{hPa}$. For this particular thin cloudy case the temperature profile (not shown) is

247 not significantly affected by clouds when compared with that from the clear sky method.

248 However, for water vapor the improvement is significant when applying the cloudy

249 sounding algorithm. This is illustrated in Figure 4 for relative humidity. The cloudy

250 retrieval captures the atmospheric moisture variation as shown by the radiosonde very

251 well, in particular below the cloud top level where improvements in relative humidity

252 values larger than $10 \%$ can be achieved. 


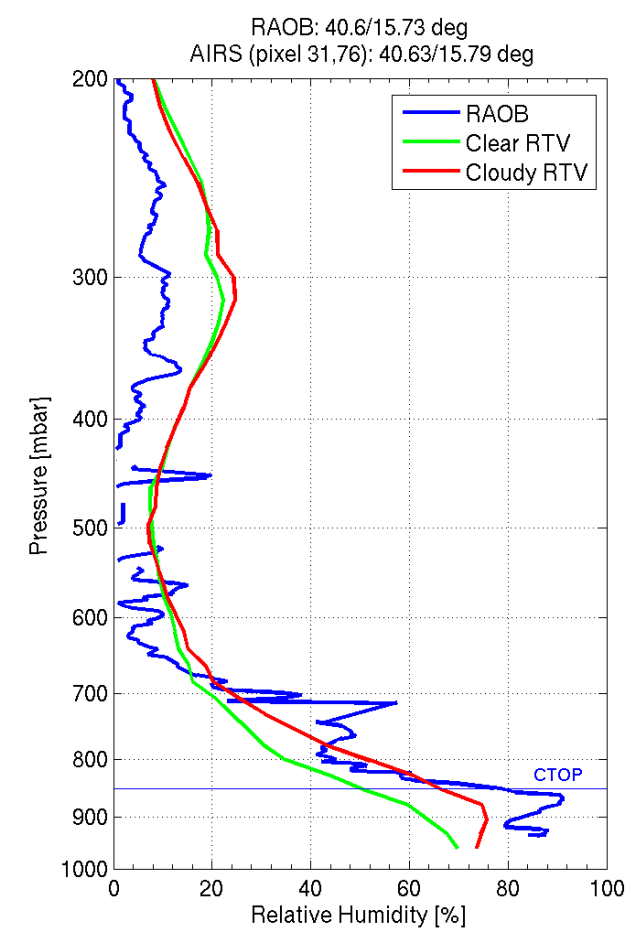

253

254 Figure 4. AIRS retrieved sounding profiles (green and red lines refer to the results from

255 the clear sky retrieval and the cloudy retrieval method, respectively) for relative humidity

256 (in percentage from $0-100 \%$ ) compared with one co-located radiosonde measurement

257 (blue). The retrieved cloud top pressure is indicated as a thin blue line. 


\section{Summary}

268 The probability of having clouds in an AIRS footprint, which is $13.5 \mathrm{~km}$ at nadir, is

269 relatively high. An approach to retrieve sounding parameters along with cloud top

270 pressure (CTP) and cloud optical thickness (COT) under cloudy skies is described in this

271 paper. A fast cloudy radiative transfer model accounting for clouds of various phases,

272 cloud particle sizes, and optical thicknesses was used to simulate cloudy radiances

273 representing the regression training set. The simulations are performed for a subset of

274 profiles from the global database with COT and effective particle size randomly assigned

275 to each profile. An eigenvector regression retrieval method is applied to obtain two sets

276 of regression coefficients (one for water clouds and one for ice clouds). The retrieval

277 product includes temperature, humidity and ozone from 0.005 to either the surface for

278 clear skies, and cloudy skies with broken and/or optically thin clouds or to the cloud top

279 level when optically thick clouds are present. AIRS retrieved CTP agrees very well with

280 the operational MODIS (MYD06) product. As for preliminary validation of the sounding

281 products, ECMWF analysis fields were used. The spatial features are well reproduced by

282 the AIRS cloudy sounding profiles. The case study involving a co-located radiosonde

283 measurement further endorses the capability and accuracy of this algorithm.

284 Future work includes more validation of the current product, sounding improvement

285 for mixed phase clouds, and sounding enhancement by using an iterative physical

286 retrieval scheme at AIRS SFOV resolution. Studies have been conducted on the

287 combination of MODIS and AIRS for cloud property retrieval [Li et al. 2004, 2005a],

288 and cloud clearing [Li et al., 2005b]; a direct sounding approach using MODIS and AIRS

289 will also be investigated. The long-term goal is to apply this methodology to new 
290 instruments like IASI and CrIS, and to support the development of other high-spectral IR

291 sounders.

292

293 Acknowledgements. This project is partially supported by NOAA GOES-R programs at

294 CIMSS. Thanks to ECMWF and NCEP for providing the atmospheric analysis fields.

295 The authors thank Professor William L. Smith at Hampton University for insightful

296 discussion and suggestions on cloudy sounding algorithm development. The helpful

297 comments provided by two anonymous reviewers are also much appreciated.

298

299

300

301

302

303

304

305

306

307

308

309

310

311 


\section{References}

313

314 Ackerman, S. A., K. I. Strabala, W. P. Menzel, R. A. Frey, C. C. Moeller, L. E. Gumley

315 (1998), Discriminating clear sky from clouds with MODIS, J. Geophys. Research-

316 Atmospheres, 103, 32141-32157.

317 Aumann, H. H., and co-authors (2003), AIRS/AMSU/HSB on the Aqua mission: design,

318 science objective, data products, and processing systems, IEEE Trans. Geosci. Remote

319 Sensing, 41, 253-264.

320 Chahine, C., and co-authors (2006), AIRS: Improving weather forecasting and providing

321 new insights on greenhouse gases, BAMS 2006.

322 Borbas, E., S. Seemann, H.-L. Huang, J. Li, W. P. Menzel (2005), “Global profile

323 training database for satellite regression retrievals with estimates of skin temperature and

324 emissivity", Proceedings of the XIV. International ATOVS Study Conference, Beijing,

325 China.

326 Heymsfield, A. J., S. Matrosov, B. Baum (2003), Ice water path - optical depth

327 relationships for cirrus and deep stratiform ice cloud layers, J. Appl. Meteorol., 42,1369-

3281390.

329 Li, J., W. P. Menzel, F. Sun, T. J. Schmit, and J. Gurka, (2004), AIRS subpixel cloud

330 characterization using MODIS cloud products. J. Appl. Meteorol., 43, 1083 - 1094.

331 Li, J., H.-L. Huang, C.-Y. Liu, P. Yang, T. J. Schmit, H. Wei, E. Weisz, L. Guan, W. P.

332 Menzel (2005a), Retrieval of cloud microphysical properties from MODIS and AIRS. $J$.

333 Appl. Meteorol., 44, 1526 - 1543. 
334 Li, J., C.-Y. Liu, H.-L. Huang, T. J. Schmit, X. Wu, W. P. Menzel, J. J. Gurka (2005b),

335 Optimal Cloud-Clearing for AIRS Radiances Using MODIS, IEEE Trans. Geosci Remote

336 Sensing, 43, 1266-1278.

337 Smith, W. L.; D. K. Zhou, H.-L. Huang, Jun Li, X. Liu, A, M. Larar, (2004): Extraction

338 of profile information from cloud contaminated radiances, ECMWF Workshop on

339 Assimilation of High Spectral Resolution Sounders in NWP, Reading, UK, 28 June-1

340 July 2004. ECMWF Workshop Proceedings. European Centre for Medium-range

341 Weather Forecasts (ECMWF), Reading, UK, 2004, pp.145-154.

342 Smith, W. L., D. K. Zhou, H.-L. Huang, H. E. Revercomb, A.M. Larar and Chris Barnett

343 (2005a): Ultra High Spectral Satellite Remote Sounding - Results from Aircraft and

344 Satellite Measurements, Proceedings of the 14th International TOVS Study Conference,

345 25-31 May, 2005, Beijing China.

346 Smith, W. L., D. K. Zhou, A. M. Larar, S. A. Mango, H. B. Knuteson, H. E. Revercomb,

347 and W. L. Smith Jr. (2005b), The NPOESS Airborne Testbed Interferometer - Remotely

348 Sensed Surface and Atmospheric Conditions during CLAMS, J. Atmos. Sci., 62, 1118 -

3491134.

350 Strabala, K. I., S. A. Ackerman, W. P. Menzel (1994), Cloud properties inferred from 8-

35112 micron data, J. Appl. Meteorol., 33, 212-222.

352 Strow, L. L., S. E. Hannon, S. De Souza-Machado, H. E. Motteler, D. Tobin (2003), An

353 overview of the AIRS radiative transfer model, IEEE Trans. Geosci. Remote Sensing, 41, $354 \quad 303-313$. 
355 Susskind, J., C. D. Barnet, J. M. Blaisdell (2003), Retrieval of atmospheric and surface

356 parameters from AIRS/AMSU/HSB data in the presence of clouds, IEEE Trans. Geosci.

357 Remote Sensing, 41, 390-409.

358 Wei, H., P. Yang, J. Li, B. B. Baum, H.-L. Huang, S. Platnick, Y. Hu, L. Strow (2004),

359 Retrieval of Semitransparent Ice Cloud Optical Thickness From Atmospheric Infrared

360 Sounder (AIRS) Measurements, IEEE Trans. Geosci. Remote Sensing, 42, 2254- 2267.

361 Weisz, E., H.-L. Huang, J. Li, S. W. Seemann, E. E. Borbas, and L. Gumley (2003),

362 AIRS Real-Time Sounding Profile Retrieval For IMAPP (International MODIS/AIRS

363 Processing Package) Users. Proc. Int. ATOVS Study Conference-XIII, St. Adele, Quebec,

364 Canada, 29 October-4 November 2003, 323-330.

365 Weisz, E., H.-L. Huang, J. Li, E. E. Borbas, K. Baggett, P. Thapliyal and G. Li (2006),

366 International MODIS/AIRS Processing Package: AIRS Applications and Products

367 (submitted to J. Appl. Remote Sens.).

368 Zhou, D. K., W. L. Smith, and A. M. Larar (2001), Surface temperature and emissivity

369 from airborne measurements of IR radiance spectra, EOS Trans. AGU, 82.

370 Zhou, D. K., W. L. Smith, X. Liu, A. M. Larar, H.-L. A. Huang, J. Li, M. J. McGill, and

371 S. A. Mango (2005), Thermodynamic and cloud parameters retrieval using infrared

372 spectral data, Geophys. Res. Lett., 32, L15805.

373 Zhou, D. K., W. L. Smith, X. Liu, A. M. Larar, S. A. Mango, H.-L. Huang (2007a),

374 Physically Retrieving Cloud and Thermodynamic Parameters from Ultraspectral IR

375 Measurements, J. Atmos. Sci., 64, 969-982.

376 Zhou, D. K., W. L. Smith, V. Cuomo, J. P. Taylor, C. D. Barnet, P. Di Girolamo, G.

377 Pappalardo, A. M. Larar, X. Liu, S. M. Newman, C. Lee, and S. A. Mango, (2007b):

378 AIRS Retrieval validation during the European AQUA Thermodynamic Experiment, (to

379 be published in the Q. J. R. Meteorol. Soc.)

380

381 
